Pacific Journal of Mathematics

A NOTE ON THE SESSILE DROP 


\title{
A NOTE ON THE SESSILE DROP
}

\author{
Thomas I. VoGeL
}

\begin{abstract}
The problem considered is that of a drop of liquid resting on a plane, where the angle of contact between the drop surface and the plane is not assumed to be constant. With no assumption on the contact angle, it is shown that the drop surface, when considered from $z_{0} / 2$ to $z_{0}$, is a graph (here $z_{0}$ is the maximum height of the drop). When the contact angle is assumed to lie in the interval $\left[0, \frac{\pi}{2}\right]$, the entire drop surface is shown to be a graph. These results also hold in zero gravity, thus applying to surfaces of constant mean curvature.
\end{abstract}

1. Non-zero gravity. The model problem is that of a drop of liquid in $\mathbf{R}^{3}$ resting on a horizontal plane $\Pi$ in a uniform gravitational field, and having varying contact angles. The free surface of the drop will have as its mean curvature an affine function of height above $\Pi$ (see [1]). More formally, let $z$ represent the coordinate perpendicular to $\Pi$ and $x$ the coordinates in $\Pi \equiv\{z=0\}$. Let $\Omega \subset\{z>0\}$ be the region in space occupied by the drop, where $\Omega$ is an open set, and let $\Sigma$ be the closure of $\partial \Omega \cap\{z>0\}$, i.e., the free surface of the drop. Then at a point $(x, z) \in \Sigma$, the mean curvature of $\Sigma$ must be $\frac{1}{2}(\kappa z+\lambda)$. Here $\kappa$ is the capillary constant, depending on the materials involved, and $\lambda$ is a Lagrange multiplier arising from the volume constraint. Since the force of gravity is directed in the negative $z$ direction, we will have $\kappa>0(\kappa<0$ is the pendent drop).

For the moment, we make no assumptions on the angle of contact between $\Sigma$ and $\Pi$. In particular, the contact angle is not assumed to be constant. The angle of contact between $\Sigma$ and $\Pi$ at a point $p \in \Sigma \cap \Pi$ is the angle between the outwardly directed normal to $\Sigma$ at $p$ and the upward normal to $\Pi$ at $p$. When talking of contact angle, it is implicitly assumed that the boundary regularity of $\Sigma$ is enough to ensure that the idea of a normal to $\Sigma$ at $p$ makes sense. If $\Pi$ is assumed to be a homogeneous plate, then the accepted theory predicts that the angle of contact is constant ([1]), from which $\mathrm{H}$. Wente proves ([5]) that the drop is rotationally symmetric. However, we have all seen drops which are not rotationally symmetric resting on reasonably clean plates (e.g., spilled coffee). Apparently there is some 
resistance to motion of the curve of contact which results in varying contact angles (see [1], [2] and [3] concerning resistive forces). The drops considered in this paper will include real-life spills as well as Wente's rotationally symmetric drops.

Instead of the specific form for mean curvature considered above, in this section we will require $\Sigma$ to be a $C^{2}$ surface, and the mean curvature of $\Sigma$ at $(x, z)$ to be a Lipschitz function $H(x, z)$ which is strictly increasing in $z$. It is also not necessary to restrict ourselves to $\mathbf{R}^{3}$; we will assume that $(x, z) \in \mathbf{R}^{n-1} \times \mathbf{R}$. I will use a procedure similar to the ones used in [5] and [6] to obtain information on $\Sigma$. Consider the horizontal plane $\{z=\zeta\}$, and let $\Omega^{r}(\zeta)$ and $\Sigma^{r}(\zeta)$ be the reflections of $\Omega$ and $\Sigma$ in $\{z=\zeta\}$ (so that $\Omega^{r}(\zeta)$ and $\Sigma^{r}(\zeta)$ are upside-down). We will call the maximum height of the drop surface $z_{0}$. As $\zeta$ decreases from $z_{0}, \Omega^{r}(\zeta) \cap\{0<z \leq \zeta\}$ will start out lying inside $\Omega$ (since $\Sigma$ is smooth). Let $\zeta_{0}$ be the smallest non-negative value of $\zeta$ with the property that $\Omega^{r}(\eta) \cap\{0<z \leq \eta\}$ is contained in $\Omega$ for all $\eta>\zeta$. Notice that $\Omega^{r}\left(\zeta_{0}\right) \cap\left\{0<z \leq \zeta_{0}\right\}$ is contained in $\Omega$.

For $\zeta_{0}>0$, we first observe that one of the following cases must occur:

(1) $\Sigma^{r}\left(\zeta_{0}\right)$ will be internally tangent to $\Sigma$ at some point $\hat{p}=(\hat{x}, \hat{z})$ $\in\left\{z=\zeta_{0}\right\}$.

(2) $\Sigma^{r}\left(\zeta_{0}\right)$ will be internally tangent to $\Sigma$ at some point $\hat{p}=(\hat{x}, \hat{z})$ $\notin\left\{z=\zeta_{0}\right\}$.

(3) $\Sigma^{r}\left(\zeta_{0}\right)$ will contact $\Sigma$ on the contact curve $\Sigma \cap \Pi$.

The proof that these are the only possibilities is essentially the same as Wente's proof of the analogous result in [5], and will be omitted. However, on closer inspection we will see that cases 1 and 2 are impossible.

Case 1. Choose a coordinate system $\left(y_{1}, \ldots, y_{n-1}, z\right)$ with $z$ as before, so that the plane tangent to $\Sigma^{r}\left(\zeta_{0}\right)$ and $\Sigma$ is $\left\{y_{n-1}=0\right\}$, and the $y_{n-1}$ axis is directed into $\Omega$. Then in an open neighborhood $N \subset\left\{y_{n-1}=0\right\}$ of $\hat{p}$, there are functions $u\left(y_{1}, \ldots, y_{n-2}, z\right)$ and $v\left(y_{1}, \ldots, y_{n-2}, z\right)$ such that $\Sigma$ is locally the graph of $u$ and $\Sigma^{r}\left(\zeta_{0}\right)$ is locally the graph of $v$. We must have $v \geq u$ in $N^{-} \equiv N \cap\left\{z<\zeta_{0}\right\}$. There will hold:

$$
\operatorname{div}(T u)=-\left(\widetilde{H}\left(y_{1}, \ldots, y_{n-2}, z\right)\right)
$$

and

$$
\operatorname{div}(T v)=-\left(\widetilde{H}\left(y_{1}, \ldots, y_{n-2}, 2 \zeta_{0}-z\right)\right)
$$


in $N^{-}$. Here

$$
\operatorname{div}(T u) \equiv \operatorname{div}\left(\frac{\nabla u}{\sqrt{1+|\nabla u|^{2}}}\right)
$$

is the mean curvature operator. $\widetilde{H}$ is introduced because of the rotation. In $N^{-}$we have $\operatorname{div}(T u)>\operatorname{div}(T v)$. As in [4], $\S 10.4$ and [5], the function $w=u-v$ will satisfy $M(w)>0$, where $M$ is a linear uniformly elliptic operator with coefficients depending on $u$ and $v$. We also have $\partial w / \partial \nu=0$ at $\hat{p}$. This contradicts Hopf's boundary point lemma if $w$ is less than zero in $N^{-}$, and if $w=0$ somewhere in $N^{-}$, we violate the strong maximum principle, since $w$ cannot be identically zero in $N^{-}$.

Case 2. If $0<\hat{z}<\zeta_{0}$, then the mean curvature of $\Sigma$ at $\hat{p}$ is strictly less than that of $\Sigma^{r}\left(\zeta_{0}\right)$ at $\hat{p}$. One can derive a contradiction as in case 1 to $\Sigma^{r}\left(\zeta_{0}\right)$ lying in $\Omega$ near $\hat{p}$, using the maximum principle, or one can proceed using the geometric definition of mean curvature, as in [6]. Using either method, one quickly obtains a contradiction.

Now that we know that case 3 must occur, it follows that $\zeta_{0} \leq z_{0} / 2$, since $\Sigma^{r}\left(\zeta_{0}\right)$ doesn't go below the plane $z=2 \zeta_{0}-z_{0}$.

TheOREM 1. Suppose that $\Omega \subset\{z>0\}$ is an open set, with $\Sigma$ the closure of $\partial \Omega \cap\{z>0\}$. Suppose that the interior of $\Sigma$ is a $C^{2}$ surface, and that the mean curvature of $\Sigma$ at $(x, z)$ is $H(x, z)$, a function which is strictly increasing in $z$. Then the surface $\Sigma \cap\left\{z_{0} / 2 \leq z \leq z_{0}\right\}$ is a graph over $\Pi$.

Proof. Suppose that this surface is not a graph. Then for some $x \in \Pi$ there are two different values of $z$ in the interval $\left\{z_{0} / 2 \leq\right.$ $\left.z \leq z_{0}\right\}$ such that $(x, z)$ lies on $\Sigma$. Call them $z_{1}$ and $z_{2}$. Then for $\zeta=\left(z_{1}+z_{2}\right) / 2, \Sigma^{r}(\zeta)$ and $\Sigma$ intersect at some point $\hat{p}$. However, this value of $\zeta$ is larger than $z_{0} / 2$, so that $\Omega^{r}(\zeta) \cap\{0<z \leq \zeta\}$ must be contained in $\Omega$, and their boundaries must be tangent at $\hat{p}$. We obtain a contradiction as in case 2 , above.

Note. In the case of a symmetric sessile drop, the result of Theorem 1 is contained in the discussion following (3.7) in [1].

THEOREM 2. If in addition to the hypotheses of Theorem 1 it is required that the angle of contact between $\Sigma$ and $\Pi$ remains in the interval $\left[0, \frac{\pi}{2}\right]$, then $\Sigma$ is a graph over $\Pi$. 
Proof. If $\Sigma$ is not a graph, then we find $\zeta_{0}$ as above. Assume first that $\zeta_{0}>0$. The point of contact $\hat{p}$ between $\Sigma^{r}\left(\zeta_{0}\right)$ and $\Sigma$ is on the contact curve $\Sigma \cap \Pi$. I claim that at $\hat{p}$, the normal to $\Sigma^{r}\left(\zeta_{0}\right)$ has a non-positive $z$ component. Suppose that this is not the case. We immediately have a contradiction, since $\hat{p}$ will be contained inside of $\Omega^{r}(\zeta)$ for $\zeta$ larger than $\zeta_{0}$, contradicting the definition of $\zeta_{0}$.

But now, using the assumption on the contact angle, we will see that both $\Sigma^{r}\left(\zeta_{0}\right)$ and $\Sigma$ are tangent at $\hat{p}$. Indeed, for $\Omega$ to contain $\Omega^{r}\left(\zeta_{0}\right) \cap\left\{0<z \leq \zeta_{0}\right\}$, we must have that the normal vector to $\Sigma$ has a non-positive $z$ component, but the contact angle assumption yields that $\Sigma$ has a non-negative $z$ component at $\hat{p}$. Thus the normal to $\Sigma$ at $\hat{p}$ is horizontal. We now obtain that the normal to $\Sigma^{r}\left(\zeta_{0}\right)$ is horizontal as well, since if the $z$ component of this vector is strictly negative, we violate the fact that $\Omega^{r}\left(\zeta_{0}\right) \cap\left\{0<z \leq \zeta_{0}\right\}$ is contained in $\Omega$.

It follows that $\Sigma$ and $\Sigma^{r}\left(\zeta_{0}\right)$ must have the same normal vector at $\hat{p}$. Indeed, if they do not, their tangent planes will cross in $\{z>0\}$, which cannot occur if $\Omega^{r}\left(\zeta_{0}\right) \cap\left\{0<z \leq \zeta_{0}\right\}$ is to be contained in $\Omega$. Thus $\Sigma$ and $\Sigma^{r}\left(\zeta_{0}\right)$ are tangent at $\hat{p}$. We obtain a contradiction as in case 2 , above. Thus $\zeta_{0}=0$.

Even though $\zeta_{0}=0$, it is still conceivable that $\Sigma$ is not a graph, in that it may contain a vertical line segment. However, this leads to the same contradiction obtained in the proof of Theorem 1.

Note. Theorem 2 is sharp in that a sessile drop surface is a graph if and only if the contact angle exceeds $\frac{\pi}{2}$ nowhere on the curve of contact, since if the contact angle exceeds $\frac{\pi}{2}$ anywhere, the drop surface obviously cannot be a graph.

2. Zero gravity. We now generalize to $H(x, z)$ which is increasing in $z$, but not necessarily strictly. This includes the case of zero gravity for the physical problem of the sessile drop, when $\Sigma$ is a surface of constant mean curvature. We can obtain the results of Theorems 1 and 2 , with some additional assumptions.

THEOREM 3. Make the same assumptions as those of Theorem 1, except that $H(x, z)$ is increasing in $z$, but not necessarily strictly. In addition, assume that $\Sigma$ is connected, and that $\Sigma \cap \Pi \neq \varnothing$. Then $\Sigma \cap\left\{z_{0} / 2 \leq z \leq z_{0}\right\}$ is a graph over $\Pi$.

Proof. In going through the procedure of $\S 1$, it is now possible that all three cases occur. An example is provided by taking $\Sigma$ to be a ball 
and $\Pi$ a plane tangent to $\Sigma$. However, I claim that if for some value of $\zeta_{0}$ cases 1 or 2 occur, then case 3 must also occur for that value of $\zeta_{0}$.

First, assume that case 1 holds. Consider the proof of the impossibility of case 1 in the case that $H(x, z)$ is strictly increasing. When we now allow $H(x, z)$ to be merely increasing, we have $\operatorname{div}(T u) \geq$ $\operatorname{div}(T v)$ in $N^{-}$, so that $M(w) \geq 0$. It follows from applying Hopf's boundary point lemma and the strong maximum principle that $w \equiv 0$ in $N^{-}$. We can now continue in this fashion to obtain that $\Sigma=\Sigma^{r}\left(\zeta_{0}\right)$ in $\left\{0 \leq z \leq \zeta_{0}\right\}$. Since we have assumed that $\Sigma \cap \Pi \neq \varnothing$, we now know that case 3 holds. We similarly can show that if case 2 applies, then we are also in case 3. The proof of Theorem 3 now follows the proof of Theorem 1 .

Note. The factor of $\frac{1}{2}$ in Theorem 3 is sharp, as shown by the example of a ball tangent to $\Pi$.

THEOREM 4. Assume the hypotheses of Theorem 3 and that the angle of contact between $\Sigma$ and $\Pi$ remains in $\left[0, \frac{\pi}{2}\right]$. Then $\Sigma$ is a graph over $\Pi$.

Proof. If $\zeta_{0}>0$, we can find a point $\hat{p} \in \Sigma^{r}\left(\zeta_{0}\right) \cap(\Sigma \cap \Pi)$ as in Theorem 3. The proof now proceeds as that of Theorem 2 .

Note. The methods of this section may be applied to [6], $\S 3$. They will extend the results of [6], $\S 3$ which are stated for surfaces of constant mean curvature to include surfaces with mean curvature as considered in the present action.

Acknowledgment. This research was partially supported by the National Science Foundation (DMS-8801515). I am grateful for the hospitality of the Mathematics department of Stanford University, where some of this work was done, and I am particularly grateful for the hospitality of Robert Finn during that visit.

\section{REFERENCES}

[1] R. Finn, Equilibrium Capillary Surfaces, Springer-Verlag, New York, Inc., New York, 1986.

[2] R. Finn and M. Shinbrot, The capillary contact angle, I: the horizontal plane and stick-slip motion, J. Math. Anal. and Appl., 123 (1987), 1-17.

[3] _ The capillary contact angle, II: the inclined plane, Math. Meth. in Appl. Sci., 10 (1988), 165-196. 
[4] D. Gilbarg and N. S. Trudinger, Elliptic Partial Differential Equations of Second Order, 2nd ed., Springer-Verlag, New York, Inc., New York, 1983.

[5] H. C. Wente, The symmetry of sessile and pendent drops, Pacific J. Math., 88 no. 2, (1980), 387-397.

[6] T. I. Vogel, Uniqueness for certain surfaces of prescribed mean curvature, Pacific J. Math., 134 (1988), 197-207.

Received September 15, 1988.

TeXas A \& M University

College Station, TX 77843 


\section{PACIFIC JOURNAL OF MATHEMATICS EDITORS}

\author{
V. S. VARADARAJAN \\ (Managing Editor) \\ University of California \\ Los Angeles, CA 90024-1555-05 \\ Herbert Clemens \\ University of Utah \\ Salt Lake City, UT 84112 \\ THOMAS ENRIGHT \\ University of California, San Diego \\ La Jolla, CA 92093
}

R. FINN

Stanford University

Stanford, CA 94305

Hermann Flaschka

University of Arizona

Tucson, AZ 85721

VAUGHAN F. R. Jones

University of California

Berkeley, CA 94720

Steven Kerckhoff

Stanford University

Stanford, CA 94305

\author{
C. C. MOORE \\ University of California \\ Berkeley, CA 94720
}

MARTIN SCHARLEMANN

University of California

Santa Barbara, CA 93106

HAROLd STARK

University of California, San Diego

La Jolla, CA 92093

\section{ASSOCIATE EDITORS}
R. ARENS
E. F. BECKENBACH
B. H. NeUmanN
F. WoLF
(1904-1989)
K. YosHIDA
(1906-1982)

\section{SUPPORTING INSTITUTIONS}

UNIVERSITY OF ARIZONA
UNIVERSITY OF BRITISH COLUMBIA
CALIFORNIA INSTITUTE OF TECHNOLOGY
UNIVERSITY OF CALIFORNIA
MONTANA STATE UNIVERSITY
UNIVERSITY OF NEVADA, RENO
NEW MEXICO STATE UNIVERSITY
OREGON STATE UNIVERSITY

UNIVERSITY OF ARIZONA

CAIVERSITY OF BRITISH COLUN UNIVERSITY OF CALIFORNIA

MONTANA STATE UNIVERSITY OREGON STATE UNIVERSITY

\author{
UNIVERSITY OF OREGON \\ UNIVERSITY OF SOUTHERN CALIFORNIA \\ STANFORD UNIVERSITY \\ UNIVERSITY OF HAWAII \\ UNIVERSITY OF TOKYO \\ UNIVERSITY OF UTAH \\ WASHINGTON STATE UNIVERSITY \\ UNIVERSITY OF WASHINGTON
}

The Supporting Institutions listed above contribute to the cost of publication of this Journal, but they are not owners or publishers and have no responsibility for its content or policies.

Mathematical papers intended for publication in the Pacific Journal of Mathematics should be in typed form or offset-reproduced (not dittoed), double spaced with large margins. Please do not use built up fractions in the text of the manuscript. However, you may use them in the displayed equations. Underline Greek letters in red, German in green, and script in blue. The first paragraph must be capable of being used separately as a synopsis of the entire paper. In particular it should contain no bibliographic references. Please propose a heading for the odd numbered pages of less than 35 characters. Manuscripts, in triplicate, may be sent to any one of the editors. Please classify according to the 1980 Mathematics Subject Classification (1985 Revision) scheme which can be found in the December index volumes of Mathematical Reviews. Supply name and address of author to whom proofs should be sent. All other communications should be addressed to the managing editor, or Elaine Barth, University of California, Los Angeles, California 90024-1555-05.

There are page-charges associated with articles appearing in the Pacific Journal of Mathematics. These charges are expected to be paid by the author's University, Government Agency or Company. If the author or authors do not have access to such Institutional support these charges are waived. Single authors will receive 50 free reprints; joint authors will receive a total of 100 free reprints. Additional copies may be obtained at cost in multiples of 50 .

The Pacific Journal of Mathematics (ISSN 0030-8730) is published monthly. Regular subscription rate: $\$ 190.00$ a year (12 issues). Special rate: $\$ 95.00$ a year to individual members of supporting institutions.

Subscriptions, orders for numbers issued in the last three calendar years, and changes of address should be sent to Pacific Journal of Mathematics, P.O. Box 969, Carmel Valley, CA 93924, U.S.A. Old back numbers obtainable from Kraus Periodicals Co., Route 100, Millwood, NY 10546.

The Pacific Journal of Mathematics at P.O. Box 969, Carmel Valley, CA 93924 (ISSN 0030-8730) is published monthly. Second-class postage paid at Carmel Valley, California 93924, and additional mailing offices. Postmaster: send address changes to Pacific Journal of Mathematics, P.O. Box 969, Carmel Valley, CA 93924.

\section{PUBLISHED BY PACIFIC JOURNAL OF MATHEMATICS, A NON-PROFIT CORPORATION}




\section{Pacific Journal of Mathematics}

Vol. 144, No. $2 \quad$ June, 1990

George E. Andrews and David M. Jackson, An algebraically derived $q$-analogue of a character sum associated with a class of semiregular

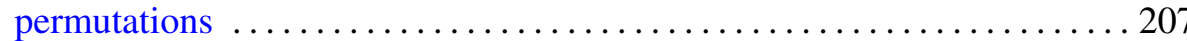

Fabio Bardelli and Andrea Del Centina, The moduli space of genus four double covers of elliptic curves is rational $\ldots \ldots \ldots \ldots \ldots \ldots \ldots \ldots 219$

Young Do Chai, An estimate of the volume of a compact set in terms of its

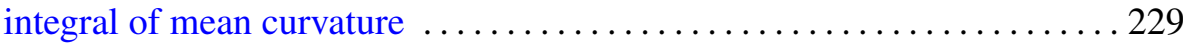

Salvador Comalada, Elliptic curves with trivial conductor over quadratic fields

Kahar El-Hussein, Résolubilité semi-globale des opérateurs différentiels invariants sur les groupes de déplacements $\ldots \ldots \ldots \ldots \ldots \ldots \ldots \ldots . \ldots 259$

David M. Goldschmidt, Classical link invariants and the Burau representation

Liliana Janicka, Radon-Nikodým problem for the variation of a vector measure

Wacław Marzantowicz, An almost classification of compact Lie groups with Borsuk-Ulam properties ............................ 299

Akira Ohbuchi, On the projective normality of some varieties of degree 5 . . 313 Ken'ichi Ohshika, Minimal measured laminations in geometric

3-manifolds

Hal Leslie Smith, A discrete Lyapunov function for a class of linear differential equations

John Samuel Spielberg, Diagonal states on $O_{2} \ldots \ldots \ldots \ldots \ldots \ldots \ldots \ldots$

Thomas Vogel, A note on the sessile drop

Gerold Wagner, On means of distances on the surface of a sphere (lower bounds) 